\title{
Relevance of Including Saturation and Position Dependence in the Inductances for Accurate Dynamic Modelling and Control of SynRMs
}

\author{
Mohamed N. Ibrahim, Student Member, IEEE, Peter Sergeant, Member, IEEE and Essam M. Rashad, \\ Senior Member, IEEE
}

\begin{abstract}
In Synchronous Reluctance Motors (SynRMs), the $d$ and $q$ - axis inductances $\left(L_{d}, L_{q}\right)$ are nonlinear functions of $d$ and $q$-axis currents $\left(i_{d}, i_{q}\right)$ and rotor position $\left(\theta_{r}\right)$. The main research question for dynamic studies of SynRMs in this paper is: how accurate should the inductance model be to have a reliable computation of dynamic behaviour and of stability limits? The stability limits are important in case of $V / f$ control without position feedback. To answer the question, we consider three cases: 1) inductances are function of $i_{d}, i_{q}$ and $\left.\theta_{r}, 2\right)$ inductances are function of $i_{d}$ and $i_{q}$, averaged over the position $\theta_{r}$ and 3) inductances are constant values, with properly chosen values. The cases 1 and 2 include saturation and cross-saturation, while case 3 does not. It is found that averaging the rotor position $\theta_{r}$ is almost not jeopardizing accuracy of the SynRM model. However, including magnetic saturation is crucial: it is observed that using constant $L_{d}$ and $L_{q}$ to represent the SynRM modelling leads to a large deviation in the prediction of the torque capability compared to the practical motor. In addition, including the magnetic saturation effect in the closed-loop control of SynRMs is necessary. Then, maximum torque per ampere (MTPA) can be achieved. Finally, the proposed method of including the magnetic saturation and the rotor position effects in the SynRM modelling, has been validated by experimental measurements.
\end{abstract}

Index Terms-- Dynamic modelling, FEM, Magnetic saturation, Rotor position effect, Stability limits, Synchronous reluctance motor, Vector control.

\section{NOMENCLATURE}

$$
\begin{array}{ll}
v_{d}, v_{q} & \begin{array}{l}
\text { Instantaneous direct and quadrature component } \\
\text { of stator voltage respectively, } \mathrm{V} .
\end{array} \\
V_{m}, I_{m} & \begin{array}{l}
\text { Maximum input voltage }(\mathrm{V}) \text { and current }(\mathrm{A}) \text { of } \\
\text { the SynRM respectively. }
\end{array}
\end{array}
$$

The authors acknowledge the Egyptian Ministry of Higher Education (Cultural Affairs and Missions Sector) and Special Research Fund of Ghent University (BOF) for the financial support during this work.

M. N. Ibrahim is with the Department of Electrical Energy, Systems and Automation, Ghent University, Ghent B-9000, Belgium, and also with Electrical Engineering Department, Kafrelshiekh University, Kafrelshiekh, Egypt (e-mail: m.nabil@eng.kfs.edu.eg).

P. Sergeant is with the Department of Electrical Energy, Systems and Automation, Ghent University, Ghent B-9000, Belgium (e-mail: peter.sergeant@ugent.be). P. Sergeant is also member of UGent EEDT Research Cluster Energy Efficient Drive Trains and Flanders Make, the strategic research center for the manufacturing industry.

E. M. Rashad is with the Department of Electrical Power and Machines, Tanta University, Tanta, Egypt (e-mail: emrashad@ieee.org). $i_{d}, i_{q} \quad$ Instantaneous direct and quadrature axis stator current respectively, A.

$L_{d d}, L_{q q}, \quad$ Direct and quadrature axis inductance of self-axis current of SynRM respectively, $\mathrm{H}$.

$L_{d q}, L_{q d,} \quad$ Direct and quadrature axis inductance of mutualaxis current of SynRM respectively, $H$.

$R_{S} \quad$ Stator resistance of the SynRM, $\Omega$.

$P, p \quad$ Number of pole pairs and differential operator $(d / d t)$ respectively.

$T_{e} \quad$ Electromagnetic torque, N.m.

$\omega_{r}, N_{r} \quad$ Mechanical speed of the rotor, $\mathrm{rad} / \mathrm{s}$ and $\mathrm{r} / \mathrm{min}$ respectively.

$\theta_{r} \quad$ Mechanical rotor position, Deg.

$\lambda_{d}, \lambda_{q} \quad$ Direct and quadrature axis flux-linkages of the SynRM as a function of $i_{d}, i_{q}$ and $\theta_{r}$ resp., V.s.

\section{INTRODUCTION}

Synchronous Reluctance Motors (SynRMs) have many $S_{\text {attractive features compared to other types of motors [1]. }}$ This is because of several advantages such as the rugged construction, the absence of rare-earth magnets and low cost; because there are no cage, windings and magnets in the rotor [2]-[5]. The SynRM behaviour depends mainly on the difference between the direct $(d)$ and quadrature $(q)$ axis inductances $\left(L_{d}, L_{q}\right)$. This difference is affected by the rotor geometry design and the magnetic material grade of the motor core. The magnetic material grade has an effect on both the $d q$-axis inductances and the core loss of the SynRM. The inductances depend on its $B H$-curve (not only maximal permeability but also saturation behaviour) [4]. It was proved that the different magnet materials result in a different SynRM output power, and can increase the rated efficiency by $2.3 \%$ when using an NO20 grade instead of an M400-50A [4]. Moreover in SynRMs, the $d q$-axis inductances are not constant, depending on the self-axis current (saturation) as well as on the other axis current (cross-saturation). In addition, the position of the rotor with respect to the stator has an influence on the value of $L_{d}$ and $L_{q}$ due to the different magnetic reluctance. Therefore, a model considering the saturation, cross-saturation and the rotor position effects is necessary for an accurate representation for the SynRM control and efficiency optimization [5]-[11].

In the literature, a lot of papers have investigated the saturation and cross-saturation effects with respect to the 
SynRM performance and control. Several models have been suggested to include the effect of the magnetic saturation for electrical machines [5]-[12]. For example, in [6], mathematical relations based on experimental measurements were proposed to include the magnetic saturation effect of the $d q$-axis inductances of the SynRM. However, the model is complex and several mathematical constants have to be obtained. In [8], a saturation modelling in $d q$-axis models of salient pole synchronous machines was proposed considering a single saturation factor. In [9], the effect of the magnetic saturation on the control of a SynRM was studied based on a single saturation factor and on measured values. However, [8] and [9] assumed that the $d q$-axis inductances saturate to the same level at all the operating conditions. In [11], the impact of cross saturation in SynRM of transverse-laminated type is studied with a mixed theoretical and experimental approach considering assumptions in the measuring of the $d q$-axis fluxlinkages relations. In [12], the authors obtained $L_{d}$ as function only of $i_{d}$ by experimental measurements, neglecting the crosssaturation effect. In addition, they assumed constant $L_{q}$.

To the best of the author's knowledge, in the literature, the magnetic saturation effect is not accurately included in the SynRM modelling especially for control and drive purposes. In addition, the rotor position effect was not investigated. The main contribution of this paper is to propose a simple and accurate model to include the magnetic saturation and rotor position effects on the SynRM modelling and control. The stability limits of the SynRM are studied as well.

\section{SATURATION, CROSS-SATURATION AND ROTOR POSITION EFFECTS ON THE FLUX-LINKAGE OF THE SYNRM}

Firstly, we investigate the effect of the magnetic saturation and rotor position on the $d q$-axis flux-linkages $\left(\lambda_{d}, \lambda_{q}\right)$ of the SynRM. The SynRM is modelled in FEM to obtain $\lambda_{d}\left(i_{d}, i_{q}, \theta_{r}\right)$ and $\lambda_{q}\left(i_{d}, i_{q}, \theta_{r}\right)$. The adopted machine has 36 slots 4 symmetrical poles with the parameters listed in [3] and [4]; therefore one pole is enough in the FEM modelling to reduce the CPU time of the calculation. Sinusoidal currents are injected in the SynRM windings. Then, $i_{d}$ and $i_{q}$ are obtained by the conventional $d q$-axis transformation method. The fluxlinkage of the phases of the SynRM is computed and hence the $d q$-axis flux-linkages are calculated.

Figures 1 and 2 illustrate the variation of the $\lambda_{d}$ and $\lambda_{q}$ of the SynRM for several rotor positions $\theta_{r}$ at different $i_{d}$ and $i_{q}$. It is evident that, for a constant current along one axis, the fluxlinkage of that axis decreases with increasing the current of the other axis, for example Fig. 1-a, at $i_{d}=10 \mathrm{~A}, \lambda_{d}$ decreases by about $12 \%$ when $i_{q}$ increases from $0 \mathrm{~A}$ to $30 \mathrm{~A}$. The reduction in the flux-linkage as a result of the increase of the current of the other axis is the well-known cross saturation effect. In fact, the amount of reduction in the flux-linkage depends on the value of the currents. This can be seen by comparing e.g Fig. $1-\mathrm{a}$ and c. The reduction in $\lambda_{d}$ of Fig. 1-c is about 3.5\% compared to about $12 \%$ in Fig. 1-a. The effect of the cross saturation is lower at high currents. This is because at higher currents, the machine becomes more saturated. In addition, it is observed that the cross-saturation effect on $\lambda_{q}$ (Fig. 2) is much stronger than on $\lambda_{d}$ (Fig. 1). Notice that increasing $i_{d}$ leads to an impressive reduction in the $\lambda_{q}$ of about $35 \%$ for low $i_{q}$ (Fig. 2-a) and of about $22 \%$ for high $i_{q}$ (Fig. 2-c). This is due to the rather low value of $\lambda_{q}$ compared with $\lambda_{d}$ (saliency factor equals about 5 at the rated stator current).

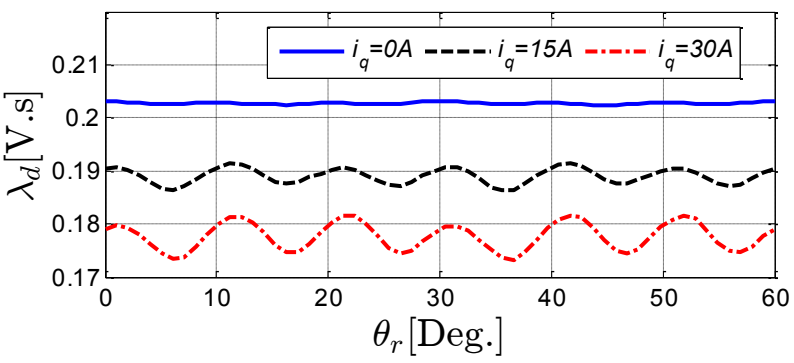

(a) $\lambda_{d}$ versus $\theta_{r}$ for constant $i_{d}=10 \mathrm{~A}$ and different $i_{q}(0,15$ and 30A).

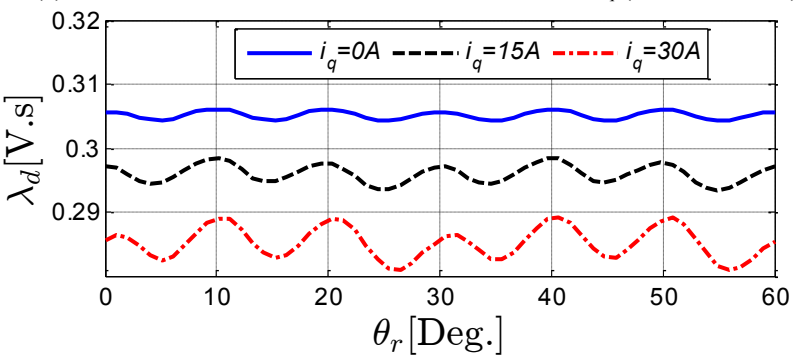

(b) $\lambda_{d}$ versus $\theta_{r}$ for constant $i_{d}=20 \mathrm{~A}$ and different $i_{q}(0,15$ and $30 \mathrm{~A})$.

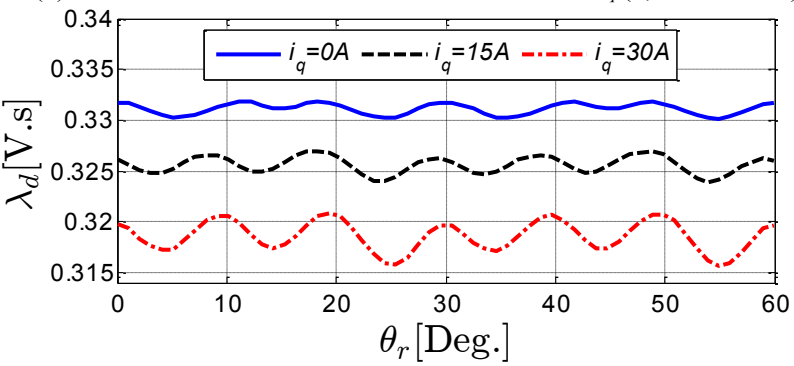

(c) $\lambda_{d}$ versus $\theta_{r}$ for constant $i_{d}=30 \mathrm{~A}$ and different $i_{q}(0,15$ and $30 \mathrm{~A})$.

Fig. 1. $d$-axis flux-linkage $\left(\lambda_{d}\left(i_{d}, i_{q}, \theta_{r}\right)\right)$ for the SynRM using FEM.

An interesting notice here is that the cross saturation does not influence the value of the flux-linkage only, but also the value of the ripple of the flux-linkage as a function of the rotor position $\theta_{r}$. The ripples of $\lambda_{d}$ and $\lambda_{q}$ increase with increasing the currents $\left(i_{d}, i_{q}\right)$ for instance, Fig. 2 -a, at $i_{q}=10 \mathrm{~A}$, the ripple of $\lambda_{q}$ is increased from $3.4 \%$ to $20 \%$ when $i_{d}$ increases from $0 \mathrm{~A}$ to $30 \mathrm{~A}$ respectively. The variation of $\lambda_{d}$ and $\lambda_{q}$ with the rotor position $\theta_{r}$ is due to the magnetic reluctance variation between the rotor (mainly the flux-barrier of the rotor) with respect to the teeth of the stator as reported in Fig. 3. For the same current level, the flux density level changes with the rotor position. For small currents, the flux chooses paths of minimum reluctance in the air gap as shown in Fig. 3-a and b. For larger currents, these paths are saturated in the same rotor positions, forcing the flux to choose paths with larger reluctance in these rotor positions as seen in Fig. 3-c and d. The ripples will have an effect on the ripple of the output torque of the SynRM. Hence, it is important to reduce the ripples of the flux-linkage to obtain a low ripple in the output torque of the machine as well as low iron losses. This can be 
done mainly by optimizing the design of the rotor flux-barrier angle with respect to the stator teeth.

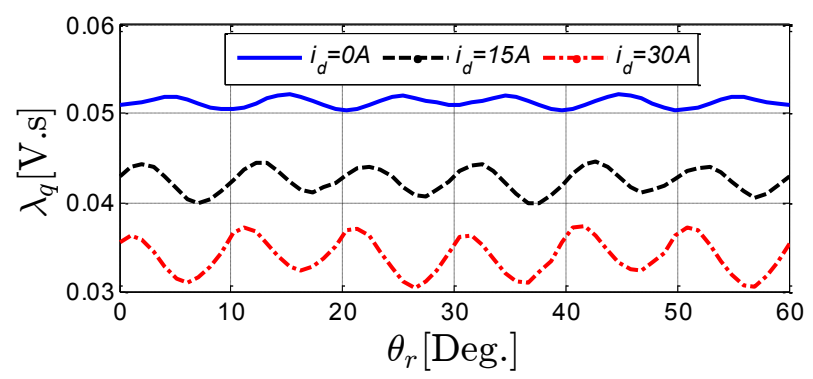

(a) $\lambda_{q}$ versus $\theta_{r}$ for constant $i_{q}=10 \mathrm{~A}$ and different $i_{d}(0,15$ and 30A).

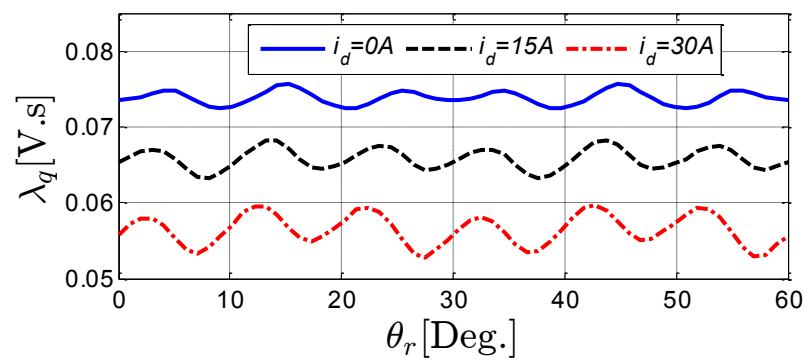

(b) $\lambda_{q}$ versus $\theta_{r}$ for constant $i_{q}=20 \mathrm{~A}$ and different $i_{d}(0,15$ and 30A).

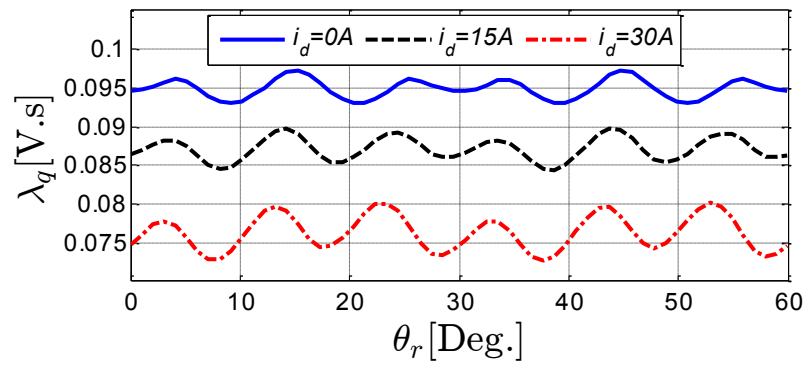

(c) $\lambda_{q}$ versus $\theta_{r}$ for constant $i_{q}=30 \mathrm{~A}$ and different $i_{d}(0,15$ and 30A).

Fig. 2. $q$-axis flux-linkage $\left(\lambda_{q}\left(i_{d}, i_{q}, \theta_{r}\right)\right)$ for the SynRM using FEM.

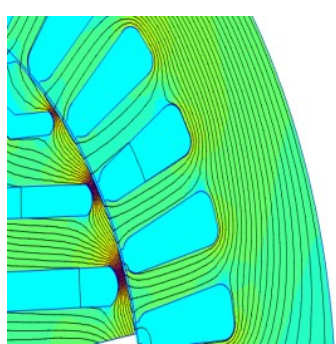

(a) $i_{d}=2 \mathrm{~A}$ and $\theta_{r}=10^{\circ}$

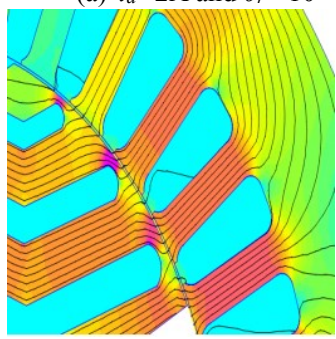

(c) $i_{d}=30 \mathrm{~A}$ and $\theta_{r}=26^{\circ}$

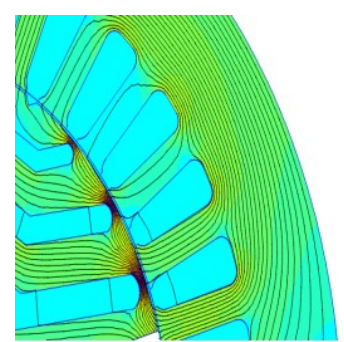

(b) $i_{d}=2 \mathrm{~A}$ and $\theta_{r}=15^{\circ}$

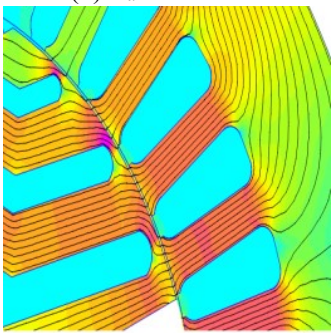

(d) $i_{d}=30 \mathrm{~A}$ and $\theta_{r}=21^{\circ}$
Fig. 3. Flux paths of SynRM for $i_{q}=10 \mathrm{~A}$ and different values for $i_{d}$ and $\theta_{r}$. The flux density scale ranges from $0 \mathrm{~T}$ (cyan colour) to $2 \mathrm{~T}$ (magenta colour).

Figure 4 shows the $d q$-axis flux-linkages $\left(\psi_{d}\left(I_{d}, I_{q}\right), \psi_{q}\left(I_{d}\right.\right.$, $\left.I_{q}\right)$ ) of the SynRM averaged with respect to the rotor positon $\left(\theta_{r}\right)$. The nonlinearity of the $d q$-axis flux-linkages as functions of the currents is noticed. In addition, the effect of the saturation on $\lambda_{q}$ is not significant and can be neglected because of the high magnetic reluctance of the $q$-axis. From Figs. 1 to 3 , it is evident that the $\lambda_{d}$ and $\lambda_{q}$ vary with both $i_{d}, i_{q}$ and $\theta_{r}$. The question is: how accurate should be the model of $\lambda_{d}$ and $\lambda_{q}$ for accurate prediction for the SynRM performance and control? This will be shown later.

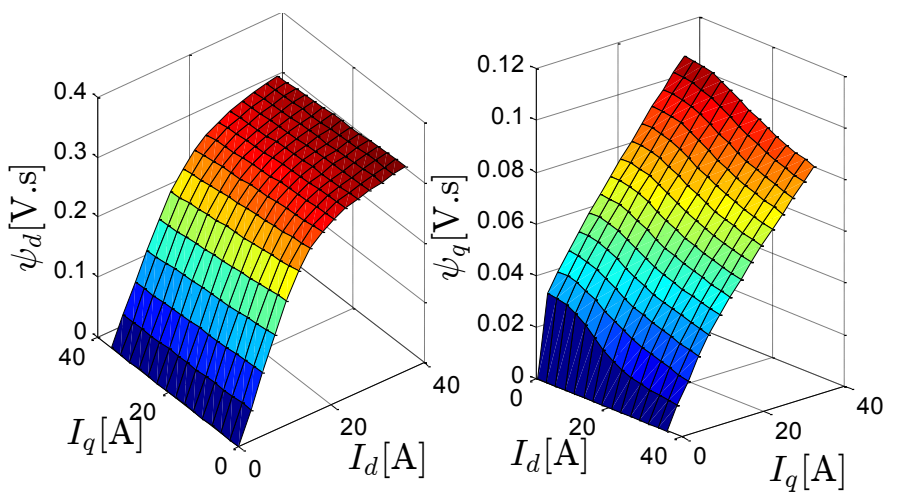

Fig. 4. $d$-axis flux-linkage $\left(\psi_{d}\left(I_{d}, I_{q}\right)\right)$ and $q$-axis flux-linkage $\left(\psi_{q}\left(I_{d}, I_{q}\right)\right)$ for the SynRM using FEM with averaging for the rotor position $\left(\theta_{r}\right)$.

\section{DYNAMIC MODEL OF THE SYNRM}

\section{a) SynRM nonlinear equations}

In order to eliminate the variation of the SynRM inductances as a function of the time, the model of SynRM is represented by the conventional $d q$-axis transformation in the rotor reference frame. The SynRM equations can be formulated by [4], [11]-[16].

$\left\{\begin{array}{l}v_{d}=R_{s} i_{d}+p \lambda_{d}\left(i_{d}, i_{q}, \theta_{r}\right)-\omega_{r} P \lambda_{q}\left(i_{d}, i_{q}, \theta_{r}\right) \\ v_{q}=R_{s} i_{q}+p \lambda_{q}\left(i_{d}, i_{q}, \theta_{r}\right)+\omega_{r} P \lambda_{d}\left(i_{d}, i_{q}, \theta_{r}\right)\end{array}\right.$

$T_{e}=\frac{3}{2} P\left(\begin{array}{l}\left(\lambda_{d}\left(i_{d}, i_{q}, \theta_{r}\right) i_{q}-\lambda_{q}\left(i_{d}, i_{q}, \theta_{r}\right) i_{d}\right)+ \\ \frac{i_{d}}{P} \frac{\partial \lambda_{d}\left(i_{d}, i_{q}, \theta_{r}\right)}{\partial \theta_{r}}+\frac{i_{q}}{P} \frac{\partial \lambda_{q}\left(i_{d}, i_{q}, \theta_{r}\right)}{\partial \theta_{r}}\end{array}\right)$

The terms on line 2 of (2) only occur if the rotor position $\left(\theta_{r}\right)$ is taken into account, and their numerically value is small compared to the terms on the first line.

The $d q$-axis voltages and currents can be obtained by:

$\left\{\begin{array}{l}v_{d}=-V_{m} \sin (\delta) \\ v_{q}=V_{m} \cos (\delta)\end{array},\left\{\begin{array}{l}i_{d}=I_{m} \cos (\alpha) \\ i_{q}=I_{m} \sin (\alpha)\end{array}\right.\right.$

where $\delta$ is the machine load angle, and $\alpha$ is the current angle as sketched in Fig. 5.

The SynRM load angle $(\delta)$ can be calculated as:

$\delta=\int\left(\omega_{r}-\omega_{s}\right) d t$

where $\omega_{s}$ is the synchronous speed of the motor, $\mathrm{rad} / \mathrm{s}$.

The power factor $(P F)$ of the SynRM can be expressed by:

$P F=\cos (\phi)=\frac{V_{d} \cos (\alpha)+V_{q} \sin (\alpha)}{\sqrt{V_{d}^{2}+V_{q}^{2}}}$

In steady state, the differential operator $(p)$ is equal to zero in (1), with an averaging with respect to the rotor position $\left(\theta_{r}\right)$. Therefore, $v_{d}, v_{q}, i_{d}, i_{q}, \lambda_{d}$ and $\lambda_{q}$ become constant values i.e. $V_{d}, V_{q}, I_{d}, I_{q}$ and $\psi_{d}$ and $\psi_{q}$ respectively. 


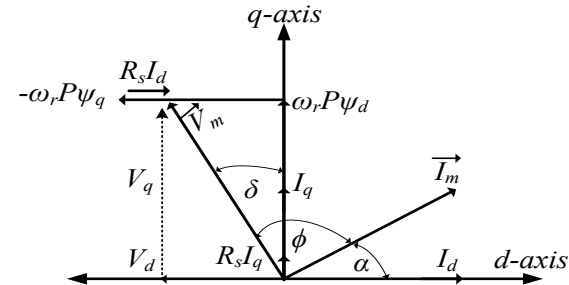

Fig. 5. Vector diagram of the SynRM in steady state.

b) Three different models for the SynRM flux-linkages

Three different models for the $d q$-axis flux-linkages $\left(\lambda_{d}, \lambda_{q}\right)$ of SynRM will be investigated:

1) Both magnetic saturation and the rotor position effects taken into account (the general and most accurate model). The $\lambda_{d}$, and $\lambda_{q}$ can be expressed by:

$$
\left\{\begin{array}{l}
\lambda_{d}\left(i_{d}, i_{q}, \theta_{r}\right)=L_{d d}\left(i_{d}, \theta_{r}\right) i_{d}+L_{d q}\left(i_{d}, i_{q}, \theta_{r}\right) i_{q} \\
\lambda_{q}\left(i_{d}, i_{q}, \theta_{r}\right)=L_{q d}\left(i_{d}, i_{q}, \theta_{r}\right) i_{d}+L_{q q}\left(i_{q}, \theta_{r}\right) i_{q}
\end{array}\right.
$$

2) Magnetic saturation effect only, without the rotor position effect. The $\lambda_{d}$, and $\lambda_{q}$ can be written by:

$$
\left\{\begin{array}{l}
\lambda_{d}\left(i_{d}, i_{q}\right)=L_{d d}\left(i_{d}\right) i_{d}+L_{d q}\left(i_{d}, i_{q}\right) i_{q} \\
\lambda_{q}\left(i_{d}, i_{q}\right)=L_{q d}\left(i_{d}, i_{q}\right) i_{d}+L_{q q}\left(i_{q}\right) i_{q}
\end{array}\right.
$$

3) Unsaturated case where the $\lambda_{d}$, and $\lambda_{q}$ can be represented by:

$$
\left\{\begin{array}{l}
\lambda_{d}=L_{d} i_{d} \\
\lambda_{q}=L_{q} i_{q}
\end{array}\right.
$$

Here, the $d$ and $q$-axis inductances $\left(L_{d}, L_{q}\right)$ are constant values.

The $d q$-axis flux-linkage relations may be obtained by experimental measurements, analytical equations, numerical calculation or by a combined solution of the analytically and experimentally obtained data [6]-[14]. In this paper, we propose to use the FEM to obtain the $d q$-axis flux-linkages $\left(\lambda_{d}\left(i_{d}, i_{q}, \theta_{r}\right), \lambda_{q}\left(i_{d}, i_{q}, \theta_{r}\right)\right)$ of the SynRM.

The FEM model is solved for different combinations of $d q$ axis currents $\left(i_{d}, i_{q}\right)$ and rotor positions $\left(\theta_{r}\right)$. The stator currents range from 0 up to the rated value. Then, three-dimensional lookup tables (LUTs) are built for the $d$ and $q$-axis fluxlinkages. The LUTs are employed in the modelling of the SynRM as described in Fig. 6. This method of implementing the $\lambda_{d}$ and $\lambda_{q}$ in the modelling of the SynRM, is simple, efficient and very fast (few seconds) for accurate studies on SynRMs with fixed geometry. However, it takes a long time to generate the LUTs from FEM. But this has to be done only once for a given machine.

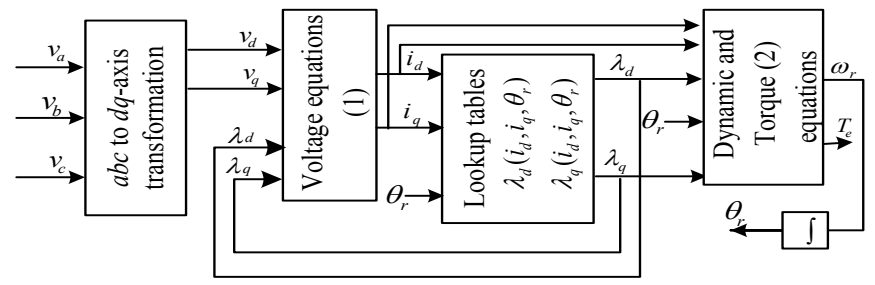

Fig. 6. Block diagram of SynRM model with lookup tables from (6), (7) or (8) for models 1,2 and 3 respectively.
From the LUTs, (6) can be achieved directly based on the required values of $i_{d}, i_{q}$ and $\theta_{r}$. In addition, (7) can be obtained by averaging LUTs over the rotor position $\left(\theta_{r}\right)$. For the unsaturated case, (8) can be obtained by assuming constant values for the $L_{d}$ and $L_{q}$ in the linear region of the fluxlinkages, see Fig. 4.

\section{VALIDATION FOR THE FEM MODEL}

The strategy of using FEM to obtain an accurate model and control for the SynRM has been validated by experimental results on the prototype having the parameters given in [3] and [4]. The complete experimental setup is shown in Fig. 7. The SynRM prototype is coupled - via a torque sensor - with an induction motor that is used as a braking load. A 3-phase power analyser is utilized for the electrical power measurement of the system.

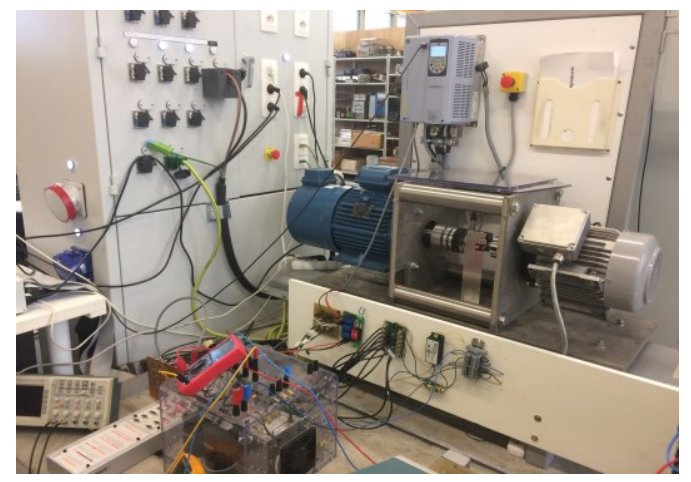

Fig. 7. Photograph of the experimental setup.

Figure 8 clarifies the computed and measured $d q$-axis fluxlinkages $\left(\psi_{d}\left(i_{d}, 0\right), \psi_{q}\left(0, i_{q}\right)\right)$ of the SynRM. The $d q$-axis fluxlinkages are measured by employing the conventional $V I$ method given in [17]. It can be deduced that the measured values have good correspondence with the simulations.

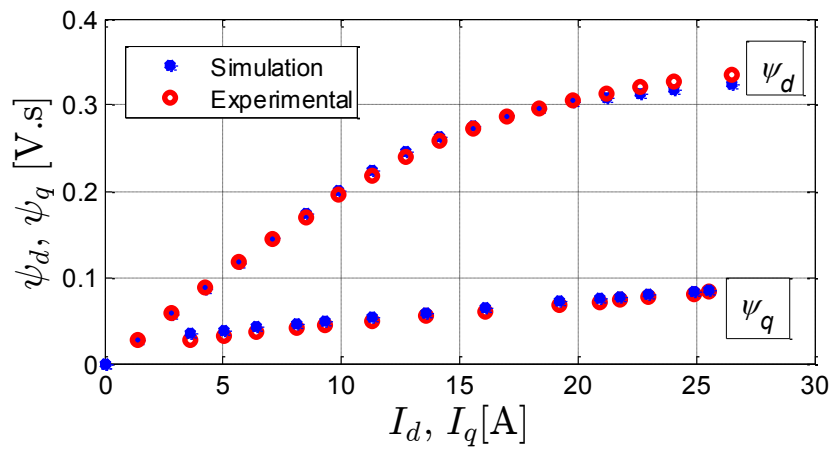

Fig. 8. Computed and measured $d q$-axis flux-linkages $\left(\psi_{d}\left(i_{d}, 0\right), \psi_{q}\left(0, i_{q}\right)\right)$ of the SynRM as a function of currents at standstill.

To obtain the measurements for the SynRM performance, a three-phase inverter controlled by a dSPACE platform (DS1103) is implemented to drive the SynRM. The field oriented control method of Fig. 15 is implemented based on space vector pulse width modulation. The measured and simulated validation results have been obtained at $2500 \mathrm{r} / \mathrm{min}$ with different loading conditions. Figure 9 shows the computed and measured $d q$-axis flux-linkages for different 
loads at constant reference $d$-axis current $i_{d} *=14.2 \mathrm{~A}$. The effect of cross saturation on the $d$-axis flux-linkage is very small because $i_{d}^{*}=14.2 \mathrm{~A}$ locates in the linear region of the $d$ axis flux-linkage (Fig. 4). The $q$-axis flux-linkage increases linearly with increasing the loading $\left(i_{q}\right)$. The computed and measured output torque of the SynRM for different loads at constant $i_{d}{ }^{*}=14.2 \mathrm{~A}$ are depicted in Fig. 10.

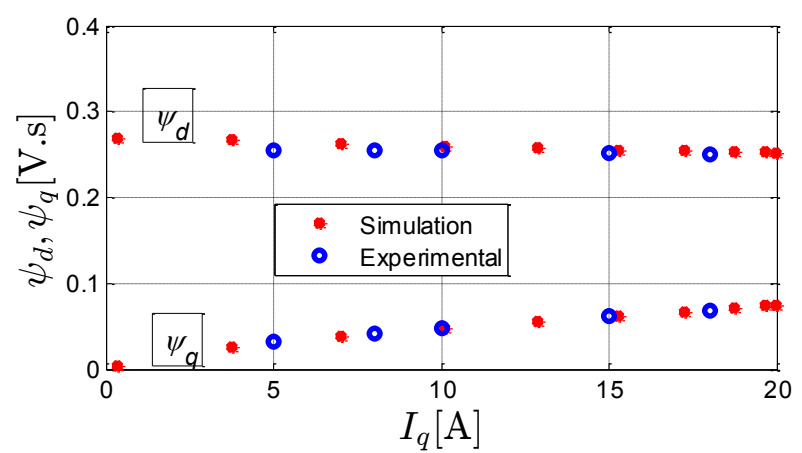

Fig. 9. Computed and measured $d q$ - axis flux-linkages $\left(\psi_{d}\left(14.2 A, i_{q}\right)\right.$, $\left.\psi_{q}\left(14.2 A, i_{q}\right)\right)$ of SynRM for different loads at $2500 \mathrm{r} / \mathrm{min}$.

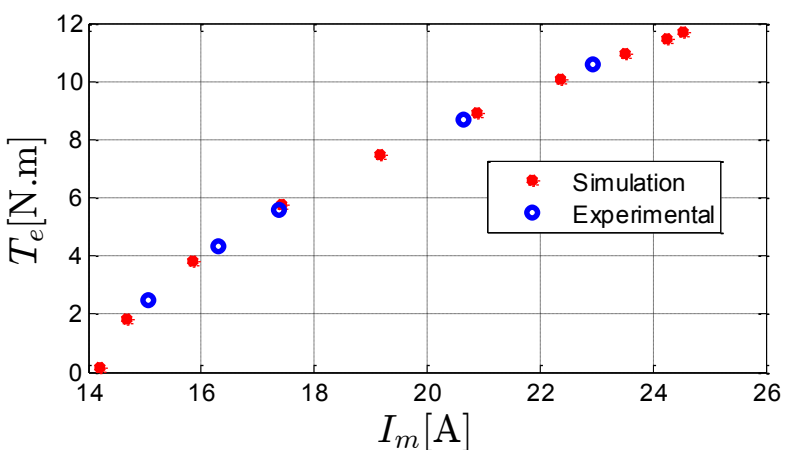

Fig. 10. Computed and measured SynRM output torque for different stator currents at $i_{d}{ }^{*}=14.2 \mathrm{~A}$ and $2500 \mathrm{r} / \mathrm{min}$.

Figure 11-(a) shows the measured (fundamental component) and the computed phase voltage of the SynRM for different current angles $\alpha$ at fixed stator current $\left(I_{m}=20 \mathrm{~A}\right)$ and fixed speed $(2500 \mathrm{rpm})$. It is clear that the phase voltage decreases with increasing current angle. This is due to the decreasing $d$ axis current which has the highest contribution on the phase voltage. The measured and computed power factors of the SynRM are shown in Fig. 11-(b). For current angles up to $56.5^{\circ}$ (the maximum torque angle of the adopted SynRM), the power factor increases as a result of increasing the load torque. Figure 11-(c) shows the measured and computed output torque of SynRM. It is evident that the output torque of the SynRM increases with increasing current angle till an optimal value then decreases again. The maximum output torque of the SynRM does not occur at the current angle of $45^{\circ}$. This proves that it is mandatory to control the SynRM in order to achieve a maximum torque per ampere. Therefore, the SynRM losses and efficiency can be improved. The efficiency of SynRM is reported in Fig. 11-(d). There is some difference between the measured and computed efficiency. This is due to some reasons: 1) the model of the simulation is supplied by sinusoidal current while the machine is supplied by a PWM inverter in the experimental, causing additional PWM losses, 2) the mechanical losses are not included in the simulations and 3) the error in the measurements. Figs. 8 to 11, there is satisfactory agreements between the measured and the computed results.
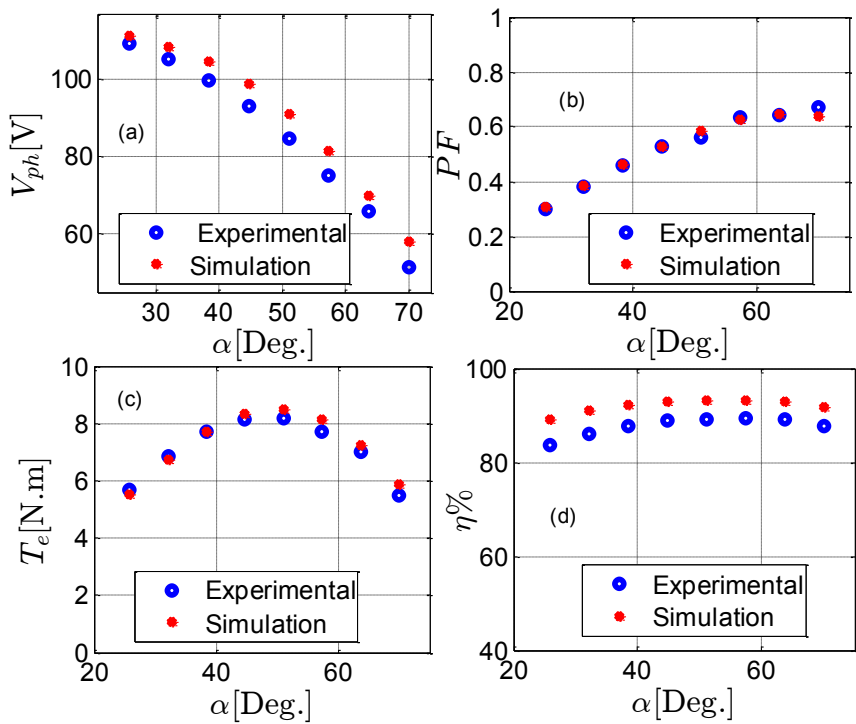

Fig. 11. Measured and computed (a) phase voltage and (b) power factor (c) output torque and (d) efficiency of SynRM versus the current angle at $I_{m}=20 \mathrm{~A}$ and $2500 \mathrm{r} / \mathrm{min}$.

\section{MAGNETIC SATURATION AND ROTOR POSITION INFLUENCE ON SYNRM PERFORMANCE}

In this section, the effect of including and neglecting the magnetic saturation and the rotor position on the SynRM performance i.e. torque capability, synchronization with the supply frequency and power factor is investigated under uncontrolled method. In addition, the impact of including the magnetic saturation in the closed loop control of SynRM is studied as well.

\section{a) Open loop uncontrolled method}

In the open loop uncontrolled method, the three different models (Sec. IV-b) for the SynRM are implemented and the performance of SynRM based on these three models is compared to show the impact of the magnetic saturation and rotor position. The voltage per hertz $\left(V_{b} / f_{b}\right)$ method is utilized to synchronize the SynRM with the supply frequency. The block diagram of the employed system is depicted in Fig. 12.

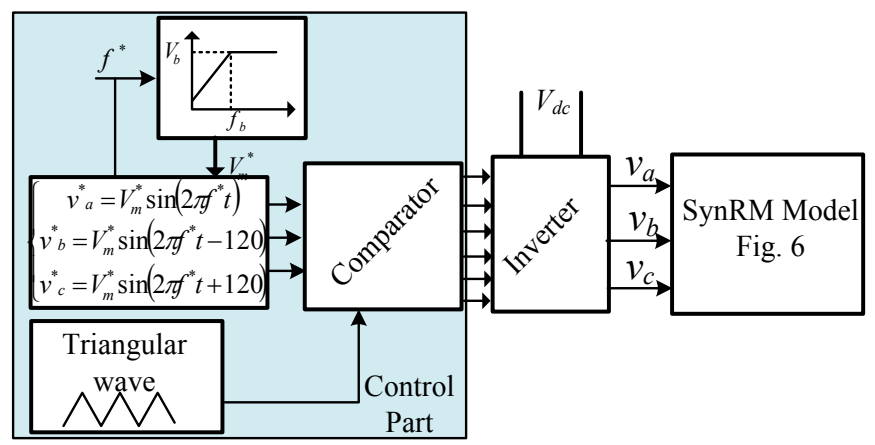

Fig. 12. Block diagram of the $V_{b} / f_{b}$ open loop control of SynRM. 
In the saturated models 1 and 2 , the $\lambda_{d}\left(i_{d}, i_{q}, \theta_{r}\right)$ and $\lambda_{q}\left(i_{d}, i_{q}\right.$, $\left.\theta_{r}\right)$ are obtained from the LUTs that are generated from the FEM. In the unsaturated model 3, the values of $L_{d}$ and $L_{q}$ are selected in the linear region of $\lambda_{d}$ and $\lambda_{q}$ i.e. neglecting the magnetic saturation and rotor position effects (see Figs. 1:4), resulting in $L_{d}=0.0203 \mathrm{H}$ and $L_{q}=0.0051 \mathrm{H}$. The moment of inertia of the SynRM is computed from FEM as listed in [3] and [4], whilst the friction coefficient is assumed to be 0.0002 $\mathrm{kg} \cdot \mathrm{m}^{2} / \mathrm{s}$.
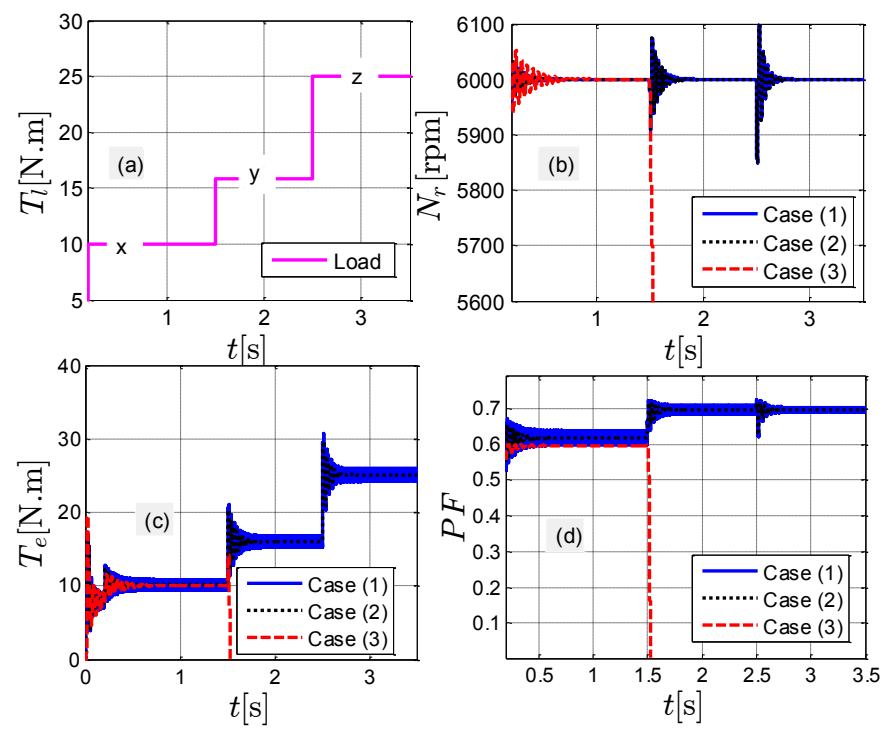

Fig. 13. Simulated run-up response ((a) load torque profile, (b) motor speed, (c) motor output torque and (d) motor power factor) of the SynRM for the three cases: with saturation and rotor position effect (case 1, blue-solid line), with only saturation effect (case 2, black-dotted line) and unsaturated (case 3, red-dashed line).

Figure 13 shows the simulated run-up response of the SynRM for the three cases i.e. considering the magnetic saturation and rotor position effects case 1, considering only the magnetic saturation effect with neglected rotor position effect case 2 , and the unsaturated case 3 . The load is changed as a stepwise function with values $\mathrm{x}=63 \%, \mathrm{y}=100 \%$ and $\mathrm{z}=$ $170 \%$ of the SynRM rated load (15.85 N.m) as shown in Fig. 13-(a). The reference speed is the rated speed $(6000 \mathrm{r} / \mathrm{min})$. At the beginning, the SynRM is synchronized with the supply frequency by $V_{b} / f_{b}$ method without loading. After the synchronization of the motor, it works under no control and then, the load characteristic of Fig. 13-(a) is applied. It is noticed in Fig. 13-(b) and (c) that the SynRM works stably and still synchronizes with the supply frequency using the model of case 1 or 2 for the different loads. However, for the unsaturated model of case 3, it doesn't work stably for the rated load or higher. In addition, the power factor of the saturated cases 1 and 2 is better than that of unsaturated case 3 as seen in Fig. 13-(d). Both the better torque capability and the higher power factor of the SynRM in cases 1 and 2 are thanks to the higher saliency ratio $\left(L_{d} / L_{q}\right)$ compared to case 3 where the inductances are constant values, especially at high load torque. The oscillations in case 1 (blue-solid line) are mainly due to the rotor position $\left(\theta_{r}\right)$ dependence of $\lambda_{d}$ and $\lambda_{q}$ (see Figs.
1 and 2). This can be understood by comparing the curves of case 1 (blue-solid line) with case 2 (black-dotted line), where the position effect is neglected, i.e where $\lambda_{d}$ and $\lambda_{q}$ are averaged over $\theta_{r}$. The higher oscillations at the instant of the step change in the load are due to the assumed damping coefficient, which is rather low.

Figure 14 manifests the simulated variation of the SynRM torque with the load angle for the three cases at the rated speed and for the similar load characteristic of Fig. 13-(a). It is evident that the machines including saturation (case 1 and 2) have a higher torque capability (30 N.m), compared to the unsaturated one (14 N.m). In addition, there is no influence on the SynRM torque capability or the stability region of the operation when neglecting the rotor positon effect (blackdotted and blue-solid curves). The stability region is the region where the load angle is less or equal than $45^{\circ}$. From Figs. 13 and 14, we learn two things: 1) it is necessary to include the magnetic saturation in the modelling of the SynRM and 2) it is not necessary to include the rotor position effect in the modelling: it only leads to a somewhat higher variation in the SynRM output torque and an increased harmonic content compared to case 1 , but it has the same stability limits and dynamic behaviour.

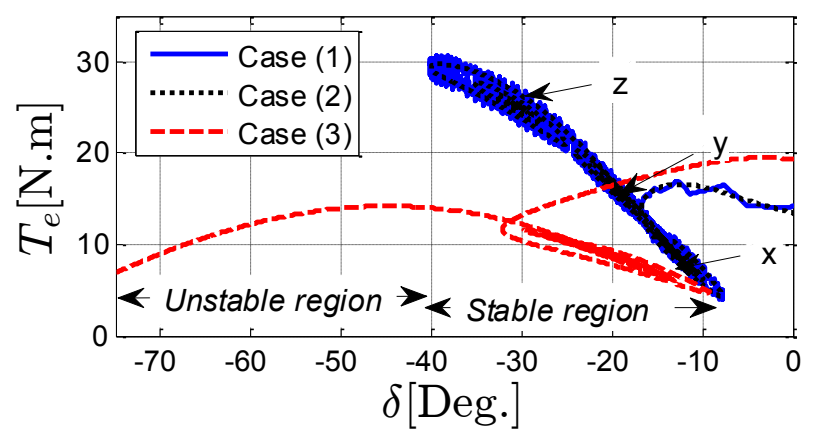

Fig. 14. The simulated variation of the motor torque with the load angle for the three cases at $6000 \mathrm{r} / \mathrm{min}$ : with saturation and position effect (blue-solid line), with only saturation effect (black-dotted line) and unsaturated (reddashed line).

\section{b) Closed loop controlled method}

In the closed loop controlled method, the SynRM is controlled by the field oriented control method based on a space vector pulse width modulation. The control part of Fig. 12 is replaced by the vector controlled block diagram described in Fig. 15. As can be seen, the reference values are the $d$-axis current component $\left(i_{d}{ }^{*}\right)$ and motor speed $\left(\omega^{*}\right)$. To minimize the SynRM losses and to enhance the efficiency, it is mandatory to control the SynRM to work at the maximum torque per ampere (MTPA) value.

To clarify the importance of including the magnetic saturation effect on the value of $i_{d}{ }^{*}$ and its influence on the machine output torque, FEM results for the adopted SynRM are presented here. Figure 16 shows the output torque of the SynRM as function of the current angle $\alpha$ (see Fig. 5) at the rated conditions i.e. a speed of $6000 \mathrm{r} / \mathrm{min}$ and different stator currents up to the rated value $\left(I_{m}=30 \mathrm{~A}\right)$. The corresponding values of $i_{d}$ and $i_{q}$ are reported in Fig. 17. The blue dash-dotted 
line in Figs. 16 and 17 represents the locus of the MTPA. On this locus, the current angle has different values and the value of $i_{d} *$ is not constant and depends on the required torque. The red-dotted line shows the MTPA locus in case of neglecting the magnetic saturation in the control of the SynRM. Here, the current angle is constant and equals $45^{\circ}$. From Fig. 16, it is observed that the SynRM can produce a higher output torque: about $8 \%$ at the rated conditions when considering the magnetic saturation in the control, compared with neglecting saturation.

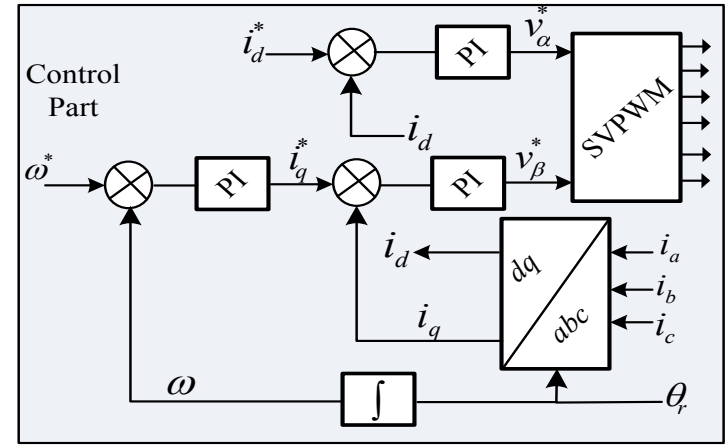

Fig. 15. Block diagram of the vector controlled closed loop method.

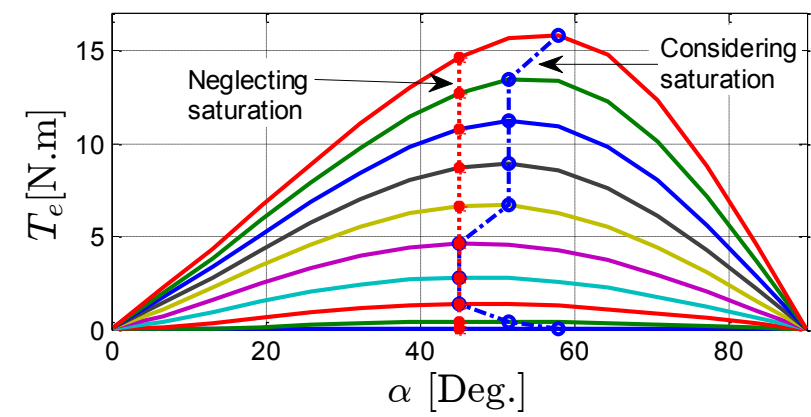

Fig. 16. The variation of the SynRM torque as a function of the current angle for different stator currents up to the rated value and at $6000 \mathrm{r} / \mathrm{min}$ using FEM.
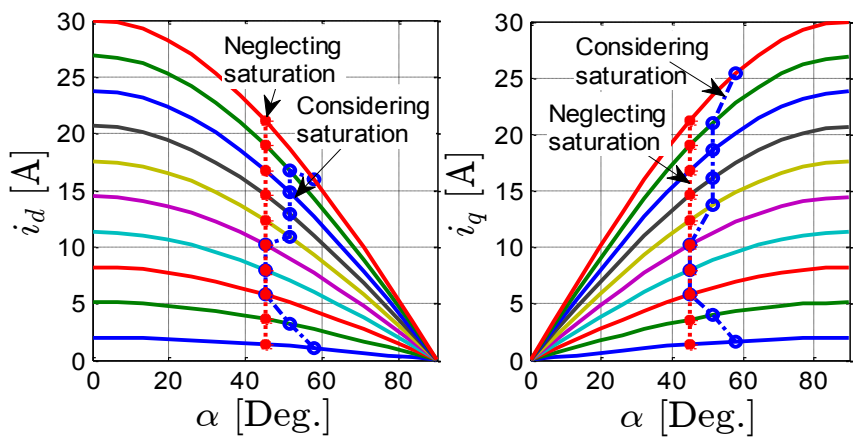

Fig. 17. The variation of the SynRM $d$ and $q$-axis current components as a function of the current angle for different stator currents up to the rated value.

Several mathematical and analytical methods to set the value of $i_{d}{ }^{*}$ can be found in the literature e.g. [6], [9] and [12]. However, these methods have several assumptions e.g. assuming that the $L_{d}$ and $L_{q}$ saturate to the same level or neglecting the cross-saturation effect. In addition, mathematical constants have to be obtained and for some cases these constants are complex and difficult. Here, we propose to use the FEM method which is explained in Secs. III and IV and is validated in Sec. V to obtain a relation between the required torque and $i_{d} *$ [13], [14]. This method is simple and accurate. In addition, no mathematical equations are needed. The only disadvantage -as mentioned before- is it takes a long time to generate the LUTs from FEM. But it is done only once.

The SynRM performance using the model of case 2 (Sec. IV-b) will be compared at the same conditions for the following two situations;

1) $i_{d} *$ is obtained by FEM and one dimensional lookup table is generated where $i_{d}^{*}=i_{d}^{*}\left(T_{e}\right)$ at the MTPA value (the blue dash-dotted line in Figs. 16 and 17). Here, the magnetic saturation effect on the control is considered.

2) $i_{d}{ }^{*}$ set equal to $i_{q}$ and thus the value of the current angle is $45^{\circ}$ (the red-dotted line in Figs. 16 and 17). Here, the magnetic saturation is neglected.

The applied load torque is a stepwise function with $63 \%$, $100 \%$ and $126 \%$ of the SynRM rated load (15.85 N.m) as seen in Fig. 18. The reference speed is the rated speed $(6000 \mathrm{r} / \mathrm{min})$. The DC bus voltage is $680 \mathrm{~V}$. The switching frequency of the inverter and the sampling time are $6.6 \mathrm{kHz}$ (33 times the rated frequency of the SynRM) and $20 \mu$ s respectively.

For situation 1, Fig. 18 shows the simulated run-up response of the SynRM considering the magnetic saturation effect on $i_{d}{ }^{*}$ at rated speed and for different loads. The corresponding currents $\left(i_{d}\right.$ and $\left.i_{q}\right)$ are reported in Fig. 19. It is clear that the value of $i_{d} *$ is varied depending on the required load torque to satisfy the MTPA condition. In addition, the motor speed follows accurately the reference value for the different loads. The motor can work stably at a load torque of $126 \%$ of the rated value.
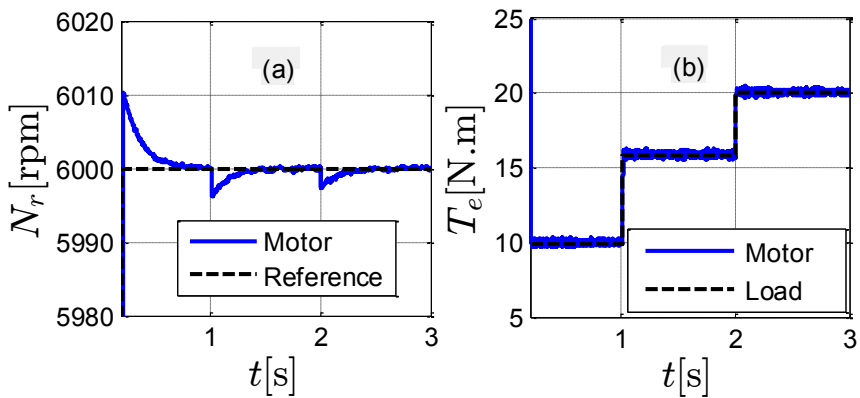

Fig. 18. Simulated run-up response ((a) speed and (b) torque) of the SynRM considering the saturation effect on the value of $i_{d}$.
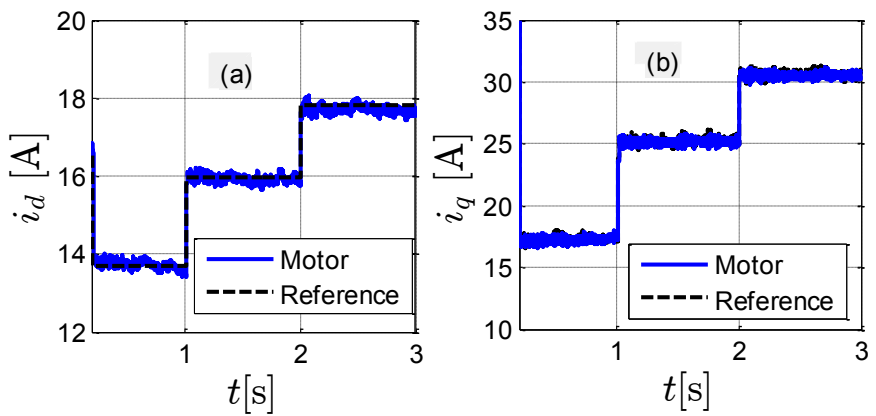

Fig. 19. The simulated response of the $i_{d}$ (a) and $i_{q}$ (b) components of the SynRM considering the saturation effect on the value of $i_{d}^{*}$ at $6000 \mathrm{r} / \mathrm{min}$. 
For situation 2, Fig. 20 shows the simulated run-up response of the SynRM neglecting the magnetic saturation effect on the value of $i_{d}{ }^{*}$ at the rated speed and for different loads. The response of the currents $i_{d}$ and $i_{q}$ is reported in Fig. 21. For the same conditions of situation 1, the SynRM can work at the rated speed only at $63 \%$ of the rated load for the given load characteristics of Fig. 18. This is clear in Figs. 20 and $21(t<=$ $1 \mathrm{~s})$. However, at the rated load or higher, the motor cannot work stably any more at the rated speed. The motor cannot follow the reference speed and therefore, a very high $i_{q}$ value (limited in the simulation by $100 \mathrm{~A}$ ) is required as shown in Figs. 20 and 21 ( $t=1 \mathrm{~s}$ to $1.3 \mathrm{~s}$ ). This is because the required load torque is higher than the torque capability of the SynRM at the given $i_{d} *$ as seen in Fig. 16. In this case, the motor must operate in the flux weakening region to work at the rated speed as shown in Figs. 20 and 21 ( $t>1.3$ s). Or, the DC bus voltage has to increase, but this solution may be not applicable in real world. The variation of the DC bus voltage may be applicable in photovoltaic systems in which there are no batteries used [18].
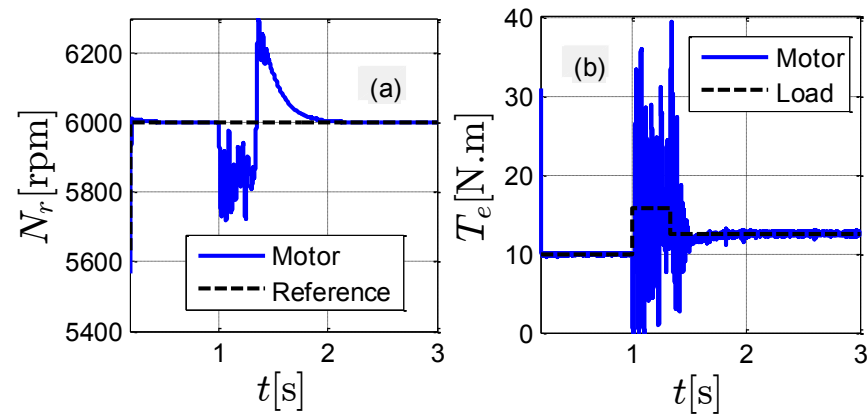

Fig. 20. Simulated run-up response ((a) speed and (b) torque) of the SynRM neglecting the saturation effect on the value of $i_{d}^{*}$.
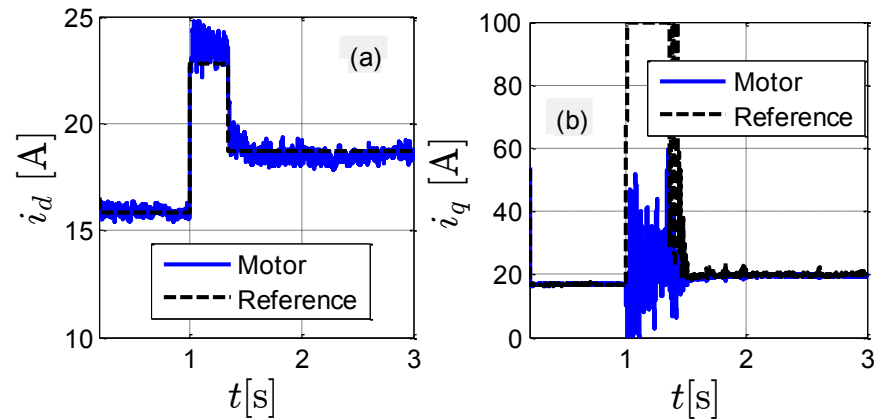

Fig. 21. The simulated response of $i_{d}$ (a) and $i_{q}$ (b) components of the SynRM neglecting the saturation effect on the value of $i_{d}$ *

\section{SYNRM PERFORMANCE AT DIFFERENT SPEEDS INCLUDING FLUX WEAKENING}

In this paragraph, the influence of the magnetic saturation on the torque capability of the SynRM, which identifies its stability region in variable speed operation, has been investigated. As usual in electrical machine control, two regions of speeds are considered. In the first region, the speed of the machine is less than or equal to the rated (base) speed. In this region, the applied voltage $\left(V_{b}\right)$ changes proportionally with the frequency $\left(f_{b}\right)$ so that $V_{b} / f_{b}$ is constant. In the second region, the speed of the motor is higher than the rated value and $V_{b}$ is kept constant at the rated value.

At steady state, the SynRM performance with considering and neglecting the magnetic saturation (case 2 and 3 Sec. IVb) is compared. Different combinations for the selection of $L_{d}$ and $L_{q}$ for the unsaturated case 3 , are considered. The $L_{d}$ is selected in the linear region of the $\lambda_{d}$, neglecting the magnetic saturation and rotor position effects (see Fig. 1-a) and thus, its value is $0.0203 \mathrm{H}$. The $L_{q}$ is selected to represent approximately the average value of $L_{q}$ in the linear, knee and saturated regions of the variation of $\lambda_{q}$ (see Fig. 2) respectively. Consequently, the $L_{q}$ values are $0.0051 \mathrm{H}, 0.0037$ $\mathrm{H}$ and $0.0032 \mathrm{H}$ respectively. Figure 22-(a) shows the variation of the maximum torque $T_{m}$ of the SynRM at different speeds from $10 \%$ up to $200 \%$ of the rated value for the saturated and unsaturated (different $L_{q}$ values at constant $L_{d}$ ) machines. The region below the curves in Fig. 22-(a) as well as in Fig. 23-(a) represents the region where the machine can work stably and synchronize with the supply frequency, while the region above the curves shows the instability region (in the direction of the plotted arrow in the figures). The stability region of the unsaturated machine increases with decreasing $L_{q}$ because of increasing the saliency ratio $\left(L_{d} / L_{q}\right)$. Moreover, the machine considering the magnetic saturation has the larger stability region (the blue solid-line) for all the considered speeds.

The machine power factor at the maximum torque $T_{m}$ for different speeds is shown in Fig. 22-(b). The machine considering the magnetic saturation (blue solid-line) has almost the better power factor compared to the unsaturated cases for all speeds less or equal than the rated value. However, the machine with $L_{q}=0.0032 \mathrm{H}$ (magenta dashedline) has the better power factor for speeds higher than the rated value.
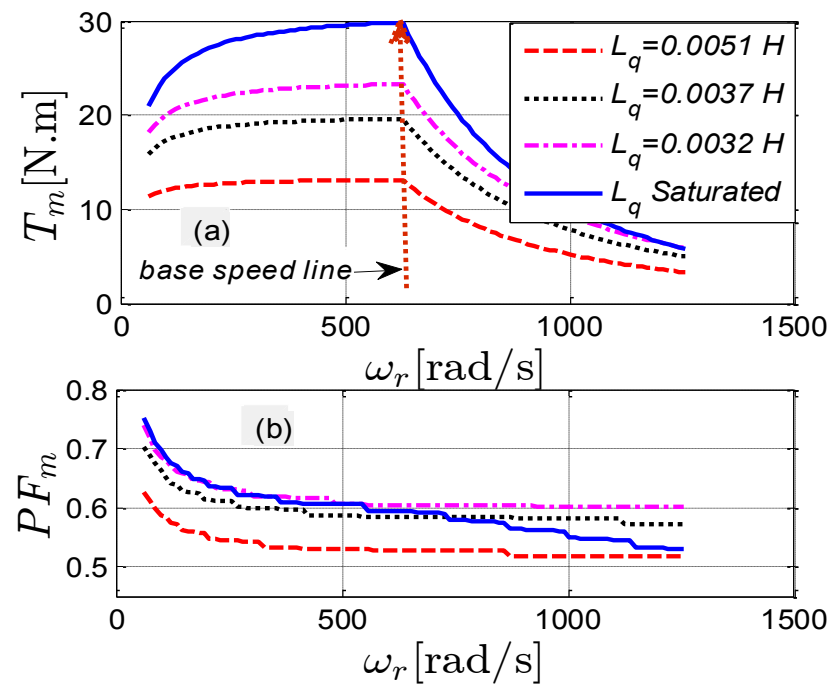

Fig. 22. Variation of SynRM maximum torque $T_{m}$ (a) and power factor $P F_{m}$ at $T_{m}$ (b) with different speeds $\omega_{r}$ for unsaturated (different $L_{q}$ and $L_{d}=0.0203 \mathrm{H}$ ) and saturated (blue solid-line) machines. (a) and (b) have the same legend. 

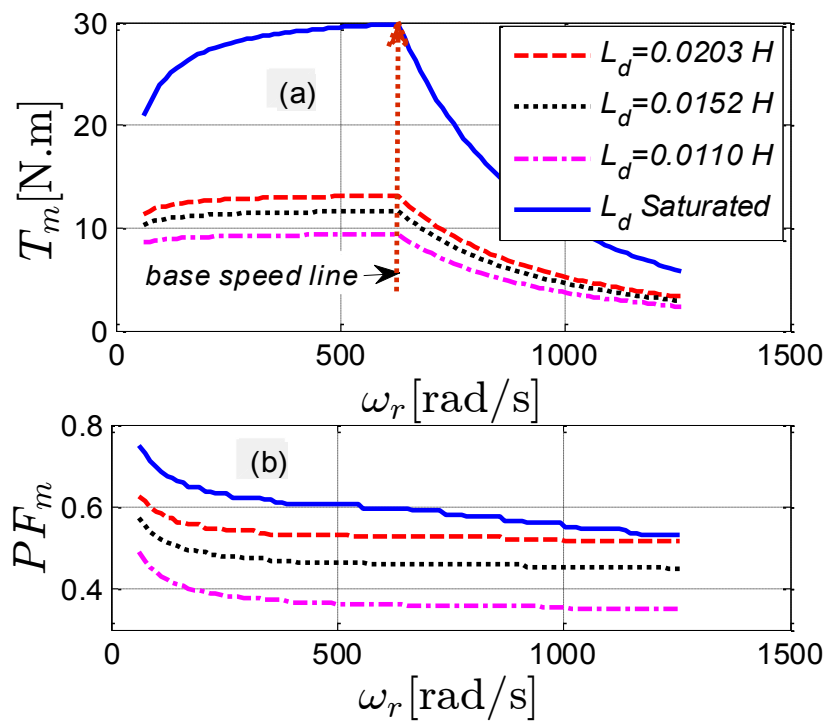

Fig. 23. Variation of SynRM maximum torque $T_{m}$ (a) and power factor $P F_{m}$ at $T_{m}$ (b) with different speed $\omega_{r}$ for unsaturated (different $L_{d}$ and $L_{q}=0.0051 \mathrm{H}$ ) and saturated (blue solid-line) machines. (a) and (b) have the same legend.

Figure 23-(a) illustrates the variation of the maximum torque $T_{m}$ of the SynRM with different speeds from $10 \%$ to $200 \%$ of the rated value for saturated and unsaturated (different $L_{d}$ values at constant $L_{q}$ ) machines. The $L_{d}$ values are $0.0203 \mathrm{H}, 0.0152 \mathrm{H}$ and $0.0110 \mathrm{H}$ to represent approximately the average value of $L_{d}$ in the linear, knee and saturated regions of the variation of $\lambda_{d}$ (see Fig. 1) respectively. The $L_{q}$ value is $0.0051 \mathrm{H}$ to represent the value of $L_{q}$ with neglecting the magnetic saturation. It is evident that the machine including the magnetic saturation (blue solid line) has the higher stability region. On the other hand, the variation of the $L_{d}$ at constant $L_{q}$ has a lower influence on the stability region compared to Fig. 22 where the $L_{q}$ varies at constant $L_{d}$. At the maximum torque $T_{m}$ of the SynRM, Fig. 23-(b) shows the variation of the power factor for different speeds. The saturated machine has the better power factor for all the considered speeds.

\section{CONCLUSIONS}

This article has investigated deeply the modelling of the SynRMs, taking into account the magnetic saturation and rotor position effects. Moreover, the stability limits of operation for the SynRM have been indicated. A simple and very fast efficient model for the SynRM has been proposed based on an accurate representing for the $d q$-axis flux-linkages. The $d q$ axis flux-linkages are computed from FEM, considering the magnetic saturation and rotor position effects. Eventually, lookup tables (LUTs) are generated for the flux-linkages and can be used in the simulations of the SynRM, obtaining an accurate prediction for its performance and control.

Three models are investigated based on an open loop uncontrolled method:

1) Considering the magnetic saturation and rotor position effects case 1 (most accurate model).

2) Considering only the magnetic saturation case 2 , without the rotor position effect.
3) Unsaturated case, where $L_{d}$ and $L_{q}$ are constants.

It was found that the SynRM torque capability and stability operation region depend mainly on the $d q$-axis flux-linkages characteristics. Including magnetic saturation in the model of a SynRM is mandatory to have an accurate prediction for its performance (output torque, power factor and stable region of operation). In addition, the selection of constant inductances $\left(L_{d}\right.$ and $\left.L_{q}\right)$ to represent simply the SynRM model is not enough and can lead to a large deviation (of about $100 \%$ for the studied cases) in the prediction of the torque capability compared with the real motor. However, the rotor position has almost no influence on the SynRM torque capability or stability region.

In the closed-loop controlled method, it is noticed that considering the magnetic saturation effect on the control of the SynRM results in an $8 \%$ increase in the output torque compared to neglecting the saturation effect for the same conditions.

Finally, the proposed strategy of including the magnetic saturation in the SynRM modelling and control has been validated by experimental measurements.

\section{REFERENCES}

[1] N. Bianchi, E. Fornasiero, and W. Soong, "Selection of PM flux-linkage for maximum low-speed torque rating in a PM- assisted synchronous reluctance machine," IEEE Trans. Ind. Appl., vol. 51, no. 5, pp. 36003608, Sep./Oct. 2015.

[2] Taghavi, and P. Pillay, "A mechanically robust rotor with transverse laminations for a wide-speed-range synchronous reluctance traction motor," IEEE Trans. Ind. Appl., vol. 51, no. 6, pp. 4404-4414, Nov./Dec. 2015.

[3] M. N. Ibrahim, P. Sergeant and E. M. Rashad, "Transient analysis and stability limits for synchronous reluctance motors considering saturation effects," in proc. 18 ICEMS, 2015, pp. 1812-1816.

[4] M. N. Ibrahim, P. Sergeant and E. M. Rashad, "Synchronous reluctance motors performance based on different electrical steel grades," IEEE Trans. Mag. vol. 51, no. 11, pp.1-4, Nov. 2015.

[5] S. Yamamoto, H. Hirahara, J. B. Adawey, T. Ara, and K. Matsuse, "Maximum efficiency drives of synchronous reluctance motors by a novel loss minimization controller with inductance estimator," IEEE Trans. Ind. Appl., vol. 49, no. 6, pp. 2543-2551, Nov./Dec. 2013.

[6] S. Yamamoto, T. Ara, and K. Matsuse, "A Method to calculate transient characteristics of synchronous reluctance motors considering iron loss and cross-magnetic saturation," IEEE Trans. Ind. Appl., vol. 43, no. 1, pp. 47-56, Jan./Feb. 2007.

[7] M. Ferrari, N. Bianchi, and E. Fornasiero, "Analysis of rotor saturation in synchronous reluctance and PM-assisted reluctance motors," IEEE Trans. Ind. Appl., vol. 51, no. 1, pp. 169-177, Jan./Feb. 2015.

[8] E. Levi, "Saturation modelling in D-Q axis models of salient pole synchronous machines," IEEE Trans. Energy Convers. vol. 14, no. 1, pp. 44-50, Mar. 1999.

[9] T. Lubin, H. Razik, and A. Rezzoug, "Magnetic saturation effects on the control of a synchronous reluctance machine," IEEE Trans. Energy Convers. vol. 17, no. 3, pp. 356-362, Sept. 2002.

[10] E. M. Rashad, "Stability Limits of Saturated Interior Permanent Magnet Motors," in conf. Power Electronics and Drives Systems, Kuala Lumpur, 2005, pp. 584 - 589.

[11] A. Vagati, M. Pastorelli, F. Scapino, and G. Franceschini, "Impact of cross saturation in synchronous reluctance motors of the transverse laminated type," IEEE Trans. Ind. Appl., vol. 36, no. 4, pp. 1039-1046, Jul./Aug. 2000.

[12] E. M. Rashad, T. S. Radwan, and M. A. Rahman, "A maximum torque per ampere vector control strategy for synchronous reluctance motors considering saturation and iron losses," in Proc. Conf. Record 2004 IEEE Ind. Appl., Oct., vol. 4, pp. 2411-2417. 
[13] L. Quéval and H. Ohsaki, "Nonlinear abc-Model for Electrical Machines Using N-D Lookup Tables," IEEE Trans. Energy Convers., vol. 30, no. 1, pp. 316-322, March 2015.

[14] M. Mohr, O. Biro, A. Stermecki, and F. Diwoky, "An improved physical phase variable model for permanent magnet machines," in Proc. IEEE 20th Int. Conf. Elect. Mach., Marseille, France, Sep. 2012, pp. 53-58.

[15] A. Kilthau and J. M. Pacas, "Parameter-measurement and control of the synchronous reluctance machine including cross saturation," in Conf. Rec. IEEE-IAS Annu. Meeting, Sept.-Oct. 2001, vol. 4, pp. 2302-2309.

[16] G. Stumberger, B. Stumberger, and D. Dolinar, "Identification of linear synchronous reluctance motor parameters," IEEE Trans. Ind. Appl., vol. 40, no. 5, pp. 1317-1324, Sept./Oct. 2004.

[17] A. Chiba and F. Nakamura, "Inductance of cageless reluctance Synchronous machines having nonsinusoidal space distribution," IEEE Trans. Ind. Appl., vol. 27, no. 1, pp. 44-51, Jan./Feb. 1991.

[18] M. Nabil, S. M. Allam, E. M. Rashad, "Modeling and design considerations of a photovoltaic energy source feeding a synchronous reluctance motor suitable for pumping systems", Ain Shams Engineering Journal, vol, 3, pp. 375-382, 2012.

\section{BIOGRAPHIES}

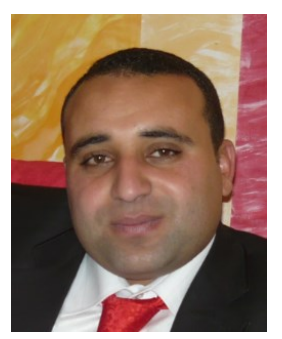

Mohamed N. Ibrahim was born in Kafrelshiekh, Egypt on September 18, 1986. He has graduated from Faculty of Engineering, Kafrelshiekh University, Egypt on 2008. He received his MSc. degree in Electrical Power and Machines Engineering from Tanta University, Egypt in 2012. Since 2012, he is working as an assistant lecturer at the Department of Electrical Engineering, Faculty of Engineering, Kafrelshiekh University, Egypt. He received Kafrelshiekh University prize for his international scientific publication in 2014 and 2016.

$\mathrm{He}$ is currently working towards the $\mathrm{PhD}$ at Ghent University, Belgium. His research interests are in Electrical Machines, Electrical Drives, Power Electronics and Renewable Energy.

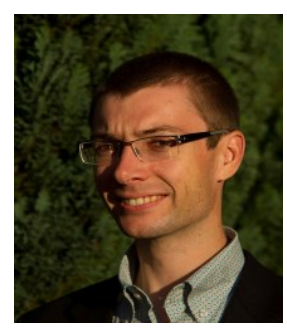

Peter Sergeant received the M.Sc. degree in electromechanical engineering in 2001, and the Ph.D. degree in engineering sciences in 2006, both from Ghent University, Ghent, Belgium.

In 2001, he became a researcher at the Electrical Energy Laboratory of Ghent University. He became a postdoctoral researcher at Ghent University in 2006 (postdoctoral fellow of the Research Foundation - Flanders) and at Ghent University College in 2008. Since 2012, he is associate professor at Ghent University. His current research interests include Numerical Methods in Combination with Optimization Techniques to Design Nonlinear Electromagnetic Systems, in particular, Electrical Machines for Sustainable Energy Applications.

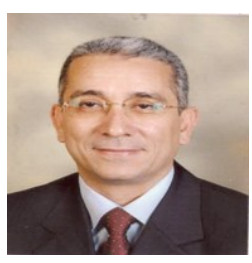

Essam M. Rashad was born in Shebin ElKom, Egypt in 1960. He received his BSc degree from the department of Electric Power and Machines Engineering., Faculty of Engineering, Shebin El-Kom, Menoufiya University, Egypt in May 1983. In 1987 and 1992 he received MSc and $\mathrm{PhD}$, respectively both from Faculty of Engineering Alexandria University, Egypt. In 1992 he has joined Faculty of Engineering, Tanta University, Egypt, where he is currently a Professor and Head of Electrical Power and Machines Engineering. From Feb. to Aug 2000, he was a visiting researcher in Faculty of Engineering, Nagasaki University, Japan. In summer 2003, he was a visiting researcher at Faculty of Engineering and Applied Science, Memorial University of Newfoundland, St. John's, NL, Canada. From 2004 to 2009, he was Head of Electrical Technology Department, Buraydah College of Technology, Kingdom of Saudi Arabia. From 2011 to 2014, he was Vice Dean for Education and Student affairs of Faculty of Engineering, Tanta University, Egypt.

Prof. Rashad research interests include Electrical Machine Analysis and Design, Electrical Drives, Power Electronics and Renewable Energy Systems. 